\title{
Prevalence of primary CNS tumors in a diagnostic setup in Nairobi, Kenya
}

\author{
Jyothi B. Lingegowda ${ }^{1}$, Ramkumar Kurpad R², Prakash H. Muddegowda ${ }^{3, *}$, Shuba Srinivasan ${ }^{4}$, \\ Manjunatha HK $^{5}$ \\ ${ }^{1}$ Professor, ${ }^{2}$ Consultant, ${ }^{3}$ Associate Professor, ${ }^{1,3}$ Dept. of Pathology, ${ }^{1,3}$ Karwar Institute of Medical Sciences, Karwar, Karnataka, \\ ${ }^{2}$ Mediheal Hospital, Kenya, ${ }^{4}$ Professor, Dept. of Medicine, Waynad Institute of Medical Sciences, Wayand, Kerala, ${ }^{5}$ Professor, \\ Dept. of Pathology, BGS Global Institute of Medical Sciences, Bangalore, Karnataka, India
}

\section{*Corresponding Author: Prakash H. Muddegowda}

Email: medicoprakash@gmail.com

Received: $19^{\text {th }}$ April, 2018

Accepted: $13^{\text {th }}$ June, 2018

\begin{abstract}
Introduction: Diagnosis of CNS tumors is often difficult for the general pathologist due to its rarity. However, high morbidity and mortality makes this the dreaded form of cancer and diagnosis requires precision to differentiate the various forms including secondaries.

Materials and Methods: Study was conducted in an independent laboratory over a period of 6 months in Nairobi, Kenya and all primary CNS neoplasms during the study period were included in the study.

Result: Amongst 42 lesions involving the CNS, 34 primary CNS neoplasms were identified. It was more common in females with a mean age of 49.41 years. Meningiomas were the most common type of CNS lesions followed by astrocytic tumors.

Conclusion: Incidence of meningiomas is high in the African population. Light microscopy is essential for initial diagnosis, however, immunohistochemistry, ultrastructural studies including molecular studies are essential to predict further management.
\end{abstract}

Keywords: Central nervous system, Neoplams, Meningioma, Astrocytoma, Kenya.

\section{Introduction}

Tumors of CNS are rare and account for less than $1-2 \%$ of all malignancies among the cancer patients. The Globocan study shows $64.9 \%$ of cancer deaths occur in less developed regions of the world and the CNS tumors with their high morbidity and mortality makes them the most dreaded form of cancer. CNS tumors diagnosis is often difficult as general pathologist lack experience and non-neoplastic processes mimic tumors and primary needs to be differentiated from secondaries. ${ }^{1-4}$ The most prevalent primary CNS tumors in adults are astrocytic tumors followed by meningiomas. Numerous classifications have been put forth to classify tumors since 1979 , which was based on light microscopy. The recent WHO classification of CNS tumors (2016) has moved beyond the light microscopy, immunohistochemistry and ultrastructural studies into the realm of incorporating molecular parameters into the classification of CNS tumors, thereby integrating both genotypic and phenotypic parameters adding a level of objectivity. Overlapping genotype like IDH mutation in both oligodendroglioma and diffuse astrocytoma (multiple susceptibility foci for gliomas seen) makes a compelling example for the new classification..$^{5-8}$

Like earlier classification, the 2016 Classification acknowledges WHO grade tumour determinations is still based on histology and genotyping each category creates new diagnostic challenges in different setups and hence integrating both genotype and phenotype is still necessary. ${ }^{5}$ The major restructuring has been done in diffuse gliomas, medulloblastomas, embryonal tumors and ependymoma with incorporation of genetically defined entities. ${ }^{69}$ In meningiomas, there were no major revisions except for introduction of brain invasion as criterion for diagnosis of atypical meningiomas, WHO grade II. Brain invasion is now used for grading, rather than staging and brain invasion alone suffices for a diagnosis of atypical meningioma similar to a histological criterion of mitotic count of 4 or more. ${ }^{5,6,9}$

Majority of setups all over the world is devoid of molecular or IHC studies and is dependent on histology. The present study was conducted to identify the prevalence of primary CNS tumors based on light microscopy findings in an independent laboratory setup and this could be one of the few studies from this part of this region in published literature.

\section{Materials and Methods}

This retrospective study was conducted over a period of 6 months (March 2016 to September 2016) in an independent laboratory in Nairobi, Kenya. Data of all primary intracranial tumors including patient's age, sex and histopathology was collected. Inclusion criteria included all primary CNS neoplasms including pituitary neoplasm's above 19 years age group. Exclusion criteria included CNS tumors in pediatric age groups, incomplete data, and inconclusive diagnosis, metastatic and non-neoplastic conditions of the CNS.

Specimens were grossed and processed according to standard procedures. All slides were stained with Haematoxylin and Eosin stain and reporting was done.

\section{Statistical Analysis}

Descriptive statistics - data was calculated as percentages. 


\section{Result}

During this period, a total of 1726 specimens were received from various departments and among these 42 specimens involved the Central nervous system. Nonneoplastic lesions formed 8 of the 42 cases. On gross examination, specimen size varied from $<0.5 \mathrm{~cm}$ to upto $4 \times 4 \mathrm{~cm}$ size, particularly with larger tumors. Multiple bits were taken and processed and slides were stained with H\&E. Amongst non-neoplastic lesions, 3 cases of tuberculoma, 2 cases of arachnoid cyst, 1 case each of epidermoid cyst, pyogenic abscess and infarct was noted.

The mean age of tumors was 49.41 years with an age range of 30-72 years. Tumors were more common during the $5^{\text {th }}$ decade. Females composed 20/34 cases with a mean age of 48.85 years with an age range of 3069 years. Amongst males 14/34 cases was seen with the mean age of 50.21 years, with a mean range of $31-72$ years.

Meningiomas were the most common type of lesions followed by astrocytic tumors. Average age group among 15 cases of meningiomas was 51.13 years with a minimum age of 31 and maximum age of 72 years. Females formed the predominant cases of meningiomas (11/15). In both males and females, meningothelial meningiomas were the commonest findings. Other variants of meningioma included psammomatous meningioma (Fig. 1), secretory meningioma (Fig. 2), atypical meningioma and transitional meningioma.

Astroyctic tumors (8/34) were the next most common lesions. Average age was 56.75 years with an age range of 47-69 years. Glioblastoma multiforme (5/8) (Fig. 3,4) was the most common type. Astrocytic tumors were again more common in females (5/8).

Other tumors found in the study were pituitary macroadenoma, Dysembryoplastic neuroectodermal tumor (Fig. 5), neurofibroma (Fig. 6), schwannoma and plasmacytoma.

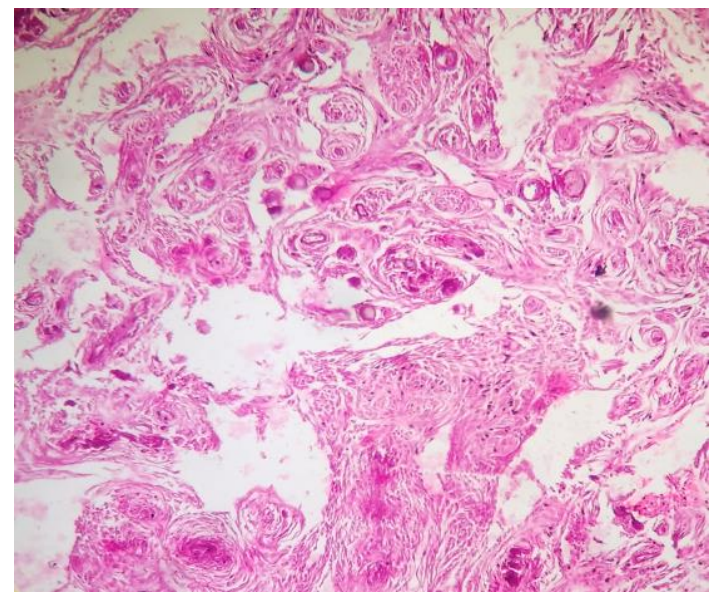

Fig. 1: Psammomatous meningioma showing psammoma bodies- 10x photomicrograph $\mathrm{HxE}$

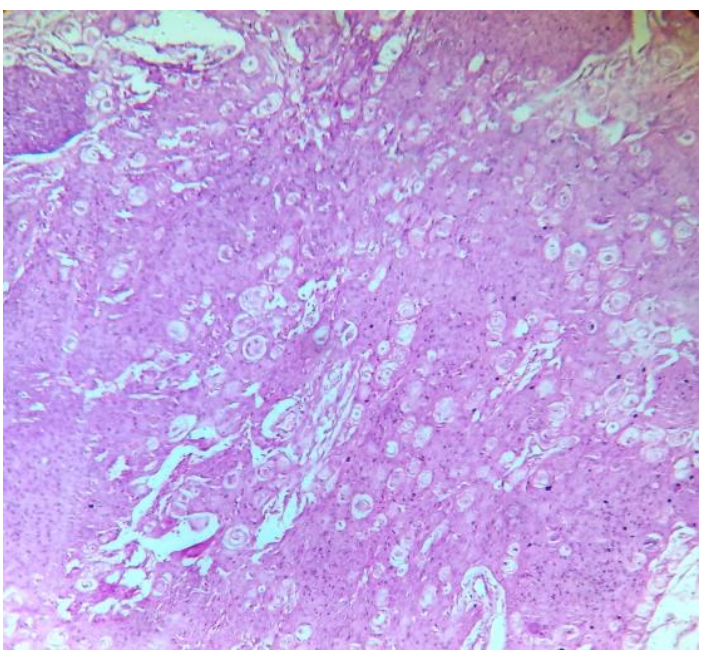

Fig. 2: Secretory meningioma showing eosionophilic secretions Photomicrograph 10x HxE

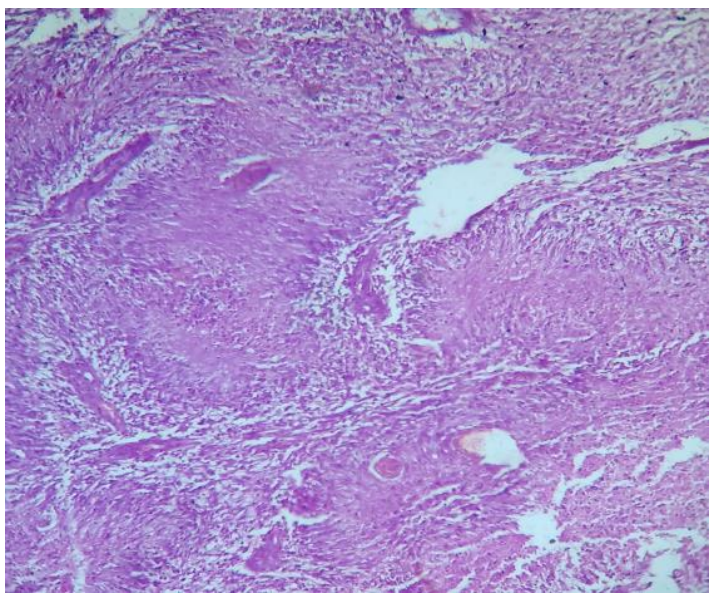

Fig. 3: Glioblastoma multiforme showing palisading necrosis Photomicrograph 10x HxE

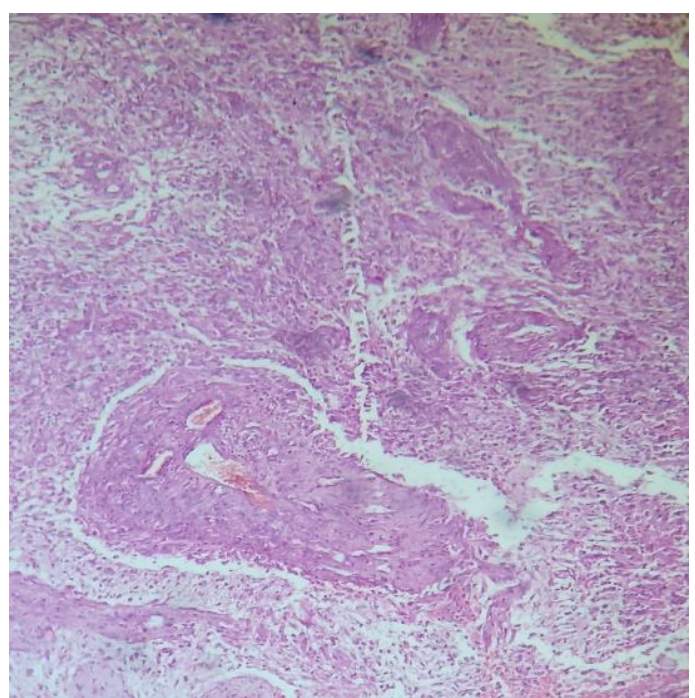

Fig. 4: Glioblastoma multiforme showing vascular proliferation and anaplasia Photomicrograph 10x HxE 


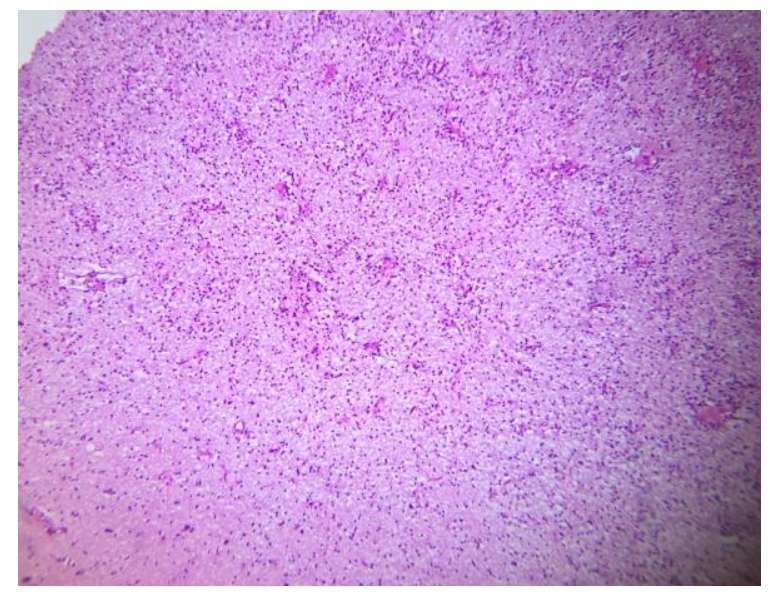

Fig. 5: Dysembryoblastic neuroectodermal tumor Photomicrograph 10x HxE

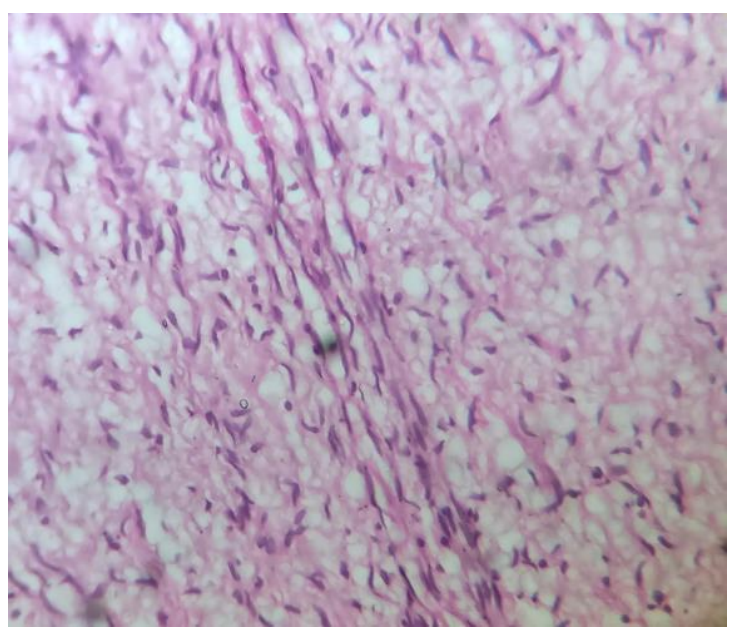

Fig. 6: Neurofibroma showing spindle cells with wavy nuclei Photomicrograph 10x HxE

\section{Discussion}

Studies about the CNS tumors are rare in the African population. Gliomas are more common followed by meningiomas similar to various studies. In the neurology centers in the African continent, CNS tumors incidence vary from $4.4 \%$ to $12 \%$ of all admissions. All over, malignant CNS tumors are more common in the pediatric age group compared to adults and they are on the rise, probably due to better detection techniques or environmental exposures. However, in developing countries like Kenya, the high gap in neurosurgical care compared to developed countries, adverse socioeconomic factors, cultural beliefs and most importantly, an alarming shortage of neurooncologists contribute to a delayed presentation and an adverse prognosis. Malignant tumors are more common in males, while benign tumors are more common in females. ${ }^{3,9-13}$

WHO 2016 CNS tumors classification is based on integrated diagnoses and along with genotyping, histopathology is necessary for classification. Genotype alone cannot be useful as mutations can overlap, for eg: oligodendroglioma and diffuse astrocytoma both have IDH mutation. Additionally, tumor grading and tumors with overlapping phenotypic and genotypic criteria require histopathological confirmation too. ${ }^{14}$ This 2016 WHO CNS tumors classification is seen as a stepping stone towards a major incorporation of molecular data in future classifications, which are more treatment oriented thereby further removing wastebasket categories. This is expected to improve and facilitate improvements in life of patients with brain tumors. ${ }^{5}$

Most common tumor in the study was meningioma followed by astrocytomas. Meningiomas are tumors arising from the arachnoid "cap" cells of the arachnoid villi and they are the most common benign primary brain tumors affecting adults. They are mostly benign, may occur intracranially or spinal and are usually clinically silent, but have a potentially high impact on morbidity of the patients. ${ }^{15-17}$ In our study, meningiomas formed 15/34 primary brain tumors, and it was more common in females. Other studies have shown similar data with occasional study showing astrocytomas to be more common. . $^{1,2,8,19}$

Research has shown multiple genetic and environmental risk factors for meningiomas. Genetically, it is known to be associated with neurofibromatosis type II and multiple endocrine neoplasia type I. Environmental risk factors principally ionizing radiation. Inconclusive data exists on use of mobile phones, hair dyes, petrochemicals, allergens, smoking, hormonal uses, etc. Meningiomas carry a better prognosis in adults compared to pediatric age group. ${ }^{16,18}$ No cases of recurrent meningiomas were noted in the study, possibly due to short duration of study or total tumor resection leading to complete cure because of the benign nature of the lesion. These findings are consistent with various studies indicating high incidence of intracranial meningiomas in Africans. ${ }^{19}$

Gliomas represent $81 \%$ of the primary malignant CNS tumors. Glioblastoma is supposed to be the most common histology and our study also shows glioblastomas to be the most common findings. Syndromes known to be associated with gliomas are neurofibromatosis type I and II, Lynch syndrome, tuberous sclerosis, etc. Other environmental risk factors are similar to meningioma. ${ }^{20,21}$

Nerve sheath tumors were very few in our study. Other studies also have shown similar findings. ${ }^{21}$ Comparison of primary CNS tumors in various studies in relation to our study is as shown in table $1 .^{1,2,8,15,22-24}$ 
Table 1: Comparison of frequently reported CNS tumors in various studies

\begin{tabular}{|c|c|c|c|}
\hline Authors & Year & Country & Most frequently reported variant \\
\hline Jaiswal J et $\mathrm{al}^{(1)}$ & 2016 & India. & Meningiomas $(23.2 \%)$ \\
\hline Ostrom QT et $\mathrm{al}^{(22)}$ & 2013 & United States of America & Meningioma (36\%) \\
\hline Sumathi $\mathrm{V}$ et $\mathrm{al}^{(8)}$ & 2016 & India & $\begin{array}{c}\text { Astrocytomas }-49 \% \\
\text { Meningiomas }-18.1 \%\end{array}$ \\
\hline Pidakala $\mathrm{P}$ et $\mathrm{al}^{(2)}$ & 2016 & India & Meningiomas $-27.1 \%$ \\
\hline${\text { Ibebuike } \mathrm{K} \text { et } \mathrm{al}^{(18)}}^{(18)}$ & 2013 & $\begin{array}{c}\text { Johanannesberg, South } \\
\text { Africa }\end{array}$ & Meningiomas $-31.8 \%$ \\
\hline Hema NA et $\mathrm{al}^{(21)}$ & 2016 & India & $\begin{array}{c}\text { Gliomas - } 44 \% \\
\text { Meningiomas - } 12 \%\end{array}$ \\
\hline Odowu $\mathrm{OE}^{(11)}$ & 2007 & Nigeria & $\begin{array}{c}\text { Meningiomas }-30 \% \\
\text { Pituitary tumors }-18 \%\end{array}$ \\
\hline Kuipers SE et $\mathrm{al}^{(24)}$ & 2013 & Suriname, South America & Meningiomas $-27.1 \%$ \\
\hline Present Study & 2016 & Kenya & Meningiomas $-44.11 \%$ \\
\hline
\end{tabular}

\section{Conclusion}

The incidence of CNS tumors is comparatively rare compared to other sites. High incidence is seen in 4th and $5^{\text {th }}$ decade with a slight female predominance. Most common primary CNS tumors seen were meningiomas followed by astrocytomas. We believe, further epidemiological studies are essential in this part of the world to provide further insight into this high incidence and possible etiological factors.

\section{Acknowledgements: None}

\section{Funding: None}

\section{Competing of Interests: None declared}

\section{References}

1. Jaiswal J, Shastry AH, Ramesh A, Chickabasaviah YT, Arimappamagan A, Santosh V. Spectrum of primary intracranial tumors at a tertiary care neurological institute: A hospital-based brain tumor registry. Neurology India. 2016;64(3):494.

2. Pidakala P, Inuganti RV, Boregowda C, Mathi A, Lakhineni S. A five-year histopathological review of CNS tumours in a tertiary centre with emphasis on diagnostic aspects of uncommon tumours. J Evid Based Med Healthc. 2016;3(51):2605-12.

3. Yeole BB. Trends in the brain cancer incidence in India. Asian Pac J Cancer Prev. 2008;9(2):267-70.

4. Latest world cancer statistics Global cancer burden rises to 14.1 million new cases in 2012: Marked increase in breast cancers must be addressed. [online] Available at: https://www.iarc.fr/en/mediacentre/pr/2013/pdfs/pr223_E.pdf [Accessed 10 Oct. 2017].

5. Fisher JL, Schwartzbaum JA, Wrensch M, Wiemels JL. Epidemiology of brain tumors. Neurologic clinics. 2007;25(4):867-90.

6. Perry A. WHO's arrived in 2016! An updated weather forecast for integrated brain tumor diagnosis. Brain tumor pathology. 2016;33(3):157-60.

7. Shete S, Hosking FJ, Robertson LB, Dobbins SE, Sanson M, Malmer B, et al. Genome-wide association study identifies five susceptibility loci for glioma. Nature genetics. 2009;41(8):899-904.
8. Sumathi V, Balakrishnan K, Krishna MS, Maheswari KU. Histopathological spectrum and grading of CNS tumours in tertiary centre: case study of 83 cases. J Evid Based Med Healthcare. 2016;3(45):2240-43.

9. Andrews NB, Ramesh R, Odjidja T. A preliminary survey of central nervous system tumors in Tema, Ghana. WAJM. 2003;22(2):167-72.

10. Ruberti RF. The surgery of Meningiomas: A review of 215 cases. African Journal of Neurological Sciences. 1995;14(1):10-3.

11. Idowu OE, Apemiye RA. Delay in presentation and diagnosis of adult primary intracranial neoplasms in a tropical teaching hospital: A pilot study. International journal of Surgery. 2009;7(4):396-8.

12. Sturm D, Orr BA, Toprak UH, Hovestadt V, Jones DT, Capper D, et al. New brain tumor entities emerge from molecular classification of CNS-PNETs. Cell. 2016;164(5):1060-72.

13. Adamson DC, Rasheed BA, McLendon RE, Bigner DD. Central nervous system. Cancer Biomark. 2010;9(16):193-210.

14. Louis DN, Perry A, Reifenberger G, von Deimling A, Figarella-Branger D, Cavenee WK, et al. The 2016 World Health Organization classification of tumors of the central nervous system: A summary. Acta neuropathologica. 2016;131(6):803-20.

15. Fonkem E, Dandashi JA, Stroberg E, Garrett D, Harris FS, El Nihum IM, et al. A retrospective analysis of meningioma in Central Texas. Journal of epidemiology and global health. 2016;6(2):87-93

16. Lakshmi SS. Meningiomas: A Clinicopathological study. International Journal of Medical Research \& Health Sciences. 2015;4(4):827-31.

17. Jethva MC, Trivedi A, Panchal M, Thakkar J. Study of cases of Intracranial Meningioma during April to September, 2014 - At PDU Govt. Medical college and Civil hospital, Rajkot, Gujarat, India. Sch J App Med Sci. 2015;3(1A):5-9.

18. Ibebuike K, Ouma J, Gopal R. Meningiomas among intracranial neoplasms in Johannesburg, South Africa: prevalence, clinical observations and review of the literature. African health sciences. 2013;13(1):118-21.

19. Ostrom QT, Bauchet L, Davis FG, Deltour I, Fisher JL, Langer CE, et al. The epidemiology of glioma in adults: a "state of the science" review. Neuro-oncology. 2014 May 19:nou087.

20. Dasgupta A, Gupta T, Jalali R. Indian data on central nervous tumors: A summary of published work. South Asian Journal of Cancer. 2016;5(3):147. 
21. Hema NA, Ravindra RS, Karnappa AS. Morphological Patterns of Intracranial Lesions in a Tertiary Care Hospital in North Karnataka: A Clinicopathological and Immunohistochemical Study. Journal of Clinical and Diagnostic Research: JCDR. 2016;10(8):EC01.

22. Ostrom QT, Gittleman H, Farah P, Ondracek A, Chen Y, Wolinsky Y, et al. CBTRUS statistical report: Primary brain and central nervous system tumors diagnosed in the United States in 2006-2010. Neuro-oncology. 2013;15(suppl 2):ii1-56.

23. Masoodi T, Gupta RK. Pattern of central nervous system neoplasms: a study of 106 cases. JK-Practitioner. 2012;17(4):42-6.
24. Kuipers SE, Kafiluddin E, Joe RT, Peerdeman S. Incidence and treatment of central nervous system tumors in Suriname. World neurosurgery. 2013;80(5):e79-83.

How to cite this article: Lingegowda J.B, Ramkumar K.R, Muddegowda P.H., Srinivasan S, Manjunatha HK. Prevalence of primary CNS tumors in a diagnostic setup in Nairobi, Kenya. Indian J Pathol Oncol. 2018;5(4):631-635. 